\title{
Eticidade e moralidade em sociedades seculares: o que pudemos e ainda podemos aprender com o 11 de setembro?
}

\author{
Ethics and moral in secular societies: \\ what we could and still can learn from \\ September 11 Attacks?
}

Roger Fernandes CAMPATO'

(iD) 0000-0001-8859-4031

Paulo Fraga da SILVA 2

(1)

0000-0003-1446-6824

João Adalberto CAMPATO JÚNIOR ${ }^{3}$

(D) 0000-0002-9026-5007

\section{R e s u mo}

\begin{abstract}
Passados 20 anos dos ataques terroristas contra os Estados Unidos, o presente artigo objetiva, a partir dos desdobramentos e dos processos de aprendizagem suscitados pelo acontecimento, analisar a possibilidade, no âmbito da secularização e consequente pluralização da vida social, responsável pela relativização das verdades religiosas e de construções metafísicas inquestionáveis, do recurso à hipótese de uma moralidade universal que se conforme aos propósitos racionais do projeto iluminista, sem que isto signifique a anulação da eticidade, inclusive da tradição religiosa. Para tanto, pretende-se estabelecer um diálogo crítico entre o formalismo moral habermasiano e o liberalismo de Engelhardt sobre o desencadeamento de competências éticas vinculadas à necessidade da tradução da linguagem religiosa para uma linguagem pública.
\end{abstract}

Palavras-chave: Ataques de 11 de setembro. Ética. Engelhardt. Habermas. Moral.

\section{Abstract}

After 20 years of the terrorist attacks against the United States, this paper aims, based on the consequences and learning processes brought on the event, to analyze the possibility, in the context of secularization and consequent pluralization of the social life, responsible for the relativization of religious truths and unquestionable metaphysical constructions, resorting to the hypothesis of a universal morality that conforms to the rational purposes of the Enlightenment project, without this meaning the reversion of ethics, including religious tradition. For this it is intended to establish a critical dialogue between Habermas's moral formalism and Engelhardt's liberalism on development of the ethical competences bound to the necessity of translation from religious language to public language.

Keywords: September 11 attacks. Ethics. Engelhardt. Habermas. Moral.

1 Universidade Presbiteriana Mackenzie, Centro de Educação, Filosofia e Teologia, Curso de Licenciatura em Filosofia. Rua da Consolação, 896, Consolação, 01302-907, São Paulo, SP, Brasil. Correspondência para/Correpondence to: R.F. CAMPATO. E-mail: <roger.campato@mackenzie.br>.

2 Universidade Presbiteriana Mackenzie, Centro de Educação, Filosofia e Teologia, Programa de Pós-Graduação em Educação, Arte e História da Cultura. São Paulo, SP, Brasil.

${ }^{3}$ Universidade Brasil, Programa de Pós-Graduação em Ciências Ambientais. São Paulo, SP, Brasil. 


\title{
In trod ução
}

\begin{abstract}
A consciência religiosa tem que, em primeiro lugar, assimilar o encontro cognitivo dissonante com outras confissões e religiões. Em segundo lugar, ela tem que se adaptar à autoridade das ciências, que possuem o monopólio social do saber referente ao mundo. Por fim, tem que consentir com as premissas do Estado Constitucional, fundamentadas em uma moral profana (Habermas, 2001, p. 14, tradução nossa) $)^{4}$.
\end{abstract}

Em tempos culturalmente acelerados, nos quais impera a necessidade, inclusive epistêmica, do esgotamento dos acontecimentos em si mesmos, a retomada de eventos como o 11 de setembro, que ocuparam nossa atenção há 20 anos, pode suscitar, quanto às intenções que a motivam, certo desconforto. Não estamos pensando naqueles que tiveram suas vidas arruinadas, cujo sofrimento com o repentino desaparecimento de entes queridos não comporta nenhuma tentativa de explicação. O desmoronamento das torres gêmeas e a investida contra o pentágono, que juntos somaram três mil mortes, devem ser recordados com qual finalidade? Para petrificar uma tragédia que, dada sua iminente possibilidade de repetição, constrange o mundo ocidental a reacender periodicamente o sinal de alerta contra inimigos que, valendo-se de estratégias de combate que beiram a barbárie, permanecem distantes de serem batidos em uma guerra travada em nome da preservação da civilização? Para justificar, a partir da assunção da perspectiva do outro, a reação de formas de vida tradicionais que não tiveram - ou jamais pretenderam tê-la -, a oportunidade de expressar reivindicações próprias no âmbito de um movimento contraditório de modernização, ao qual, sem escolha, foram submetidas? Em suma, para declarar a derrocada definitiva do projeto iluminista, que uma vez ousou vislumbrar uma ordem cosmopolita em que a convivência harmônica entre díspares estaria assegurada pelo predomínio da razão? Ou, pelo contrário, não estaríamos autorizados a utilizar a data para, desde um balanço dos dois últimos decênios, insistir no esforço para identificar caminhos que possam nos levar, sem pressupor modos de uniformização que atentem contra a alteridade, ao encontro dos que nos são, de um ponto de vista moral, estranhos, embora muitas vezes estejam bem perto de nós, na residência ao lado?

A última alternativa - a única que parece desencadear processos de aprendizagem vinculados ao desenvolvimento de competências éticas, portanto, à expansão do horizonte de um mundo social ao qual (re)descobrimos pertencer, o que compele à atualização de nossa autocompreensão -, consiste também, ao que tudo indica, naquela mais propensa ao malogro, considerado o desafio que lhe é imanente. Seu background confunde-se com o status jurídico obtido pelo pluralismo ideológico, transformado em prerrogativa quando do estabelecimento dos alicerces normativos do Estado liberal constitucional.

Doravante, em vez da substancialidade universal da religião ou de algo que o valha, a legitimidade dos elementos constituintes do poder adviria da primordialidade compartilhada entre democracia e direitos humanos. Com isso, se esvai a certeza antecipada, assumida por instituições públicas, contida no conteúdo moral de discursos que se refugiam no dogmatismo de um ponto de vista que, julgando-se privilegiado pelo acesso exclusivo a supostas verdades compreensíveis somente mediante revelação, arrogava-se a incumbência - e, somada a ela, o direito -, de determinar o que seria inquestionavelmente bom para todos.

Descartada a unidade proporcionada pela singularidade da fé, a democracia - a disputa em torno de interesses divergentes que, na melhor das hipóteses, chegam a um acordo sempre passível

\footnotetext{
${ }^{4}$ No original: Das religiöse Bewusstsein muss erstens die kognitiv dissonante Begegnung mit anderen Konfession und anderen Religionen verarbeiten. Es muss sich zweitens auf die Autorität von Wissenschaften eistellen, die das geselschaftliche Monopol an Weltwissen innehaben. Schlie lich muss es sich die Prämissem des Verfassungsstaates einlassen, die sich aus einer profanen Moral begründen (Habermas, 2001, p. 14).
} 
de revisão -, estaria em condições de assegurar formas de solidariedade e de compromisso tão sólidas e dignas de confiança quanto as disponibilizadas de antemão pela religião. Caso pretendamos ser mais contundentes: que espécie de universalidade, desde que ainda possível utilizar o termo, a secularização lega para nossas expectativas autênticas?

Eis as feições do nó górdio com o qual este século tem que lidar. A recompensa para a resolução do impasse não passa mais pela garantia da conquista do poder, mas sim pela reabilitação política da hipótese de uma coexistência pacífica entre valores prima facie inconciliáveis. Talvez a história tenha proporcionado uma oportunidade para que enfim o propósito da lenda venha à tona: a eficiência ensinada pelo cortar, a resposta mais simples e rápida aos sucessivos insucessos para desatar o nó, significa o triunfo do engano, de um embuste que já se revela no instante mesmo em que o desvencilhar-se é tomado como impossível.

Encontrado o princípio, desde então a cena pública é ocupada por variações da ideia de que o racional habita a descomplicação do que se comprovou eficaz. A curto prazo, elimina-se o problema. Calado ou assimilado, o discordante, seja como for, deixa de se manifestar. Corresponde a esta unilateralidade a sensação efêmera de bem-estar material ou espiritual. Contudo, ainda existentes, os fios sociais que compõem a substância do político continuam a se entrelaçar até reconstituir - desta feita, de modo mais acentuado -, a junta apartada. A constelação paradoxal, plena de atritos, ressurge e, com ela, a necessidade de decifrar o enigma. A reincidência do problema já não justificaria o voltar a insistir no desatamento do nó? Esta opção abrangeria racionalidade? ${ }^{5}$

\section{Formas de vida plurais em Engelhardt e em $\mathrm{H}$ a bermas}

Cada qual a sua maneira, Engelhardt e Habermas mostram-se convencidos de que a pluralidade característica da sociedade secular traz consigo empecilhos que exigem capacidades de discernimento que não se acham entre as que podem ser assimiladas à luz da aplicação de diretrizes ordinárias. Em se tratando do modo como as linhas da moral se enlaçam entre si e com outras, o saber especializado, o empreendimento científico, teria pouco a sinalizar. Se o conhecimento do mundo natural cumpriu o seu intento, o do mundo social conservar-se-ia deficitário.

Decerto, o filósofo americano, nos escritos dirigidos à Bioética ${ }^{6}$, declara posições mais radicais do que as defendidas por seu contemporâneo alemão. No contexto da premente diferenciação entre o liberalismo do primeiro e o republicanismo do segundo, tal veemência converte-se em desvantagem teórica quando se infere que ela deriva de uma concepção de razão ainda circunscrita, no campo ético-moral, aos limites de uma certa herança ontológica. Sob as experiências profanas, não há mais um ponto fixo, idêntico a todos, inclusive àqueles que não podem localizá-lo, do qual a materialidade irrefutável do discurso normativo possa ser extraída. No frigir dos ovos, pouco importa se o que desvanece é o papel sagrado das religiões monoteístas ou a diligência da metafísica em se assenhorear da totalidade

\footnotetext{
${ }^{5}$ Nos valemos aqui, com os distanciamentos que se impuseram em razão do tema e do percurso delineados, da abordagem proposta por Negt e Kluge (1992) para tratar, sob a nítida influência da lógica hegeliana, das linhas de medida, quase sempre nodais, em política. Com certa insistência, eles enfatizam que os fios sociais que definem o elemento político visam, uma vez deslindados, produzir comunidade (Gemeinwesen), lição que a política continua a ignorar. Na língua portuguesa, deslindar significa tanto esclarecer quanto destrinçar. Por fim, cumpre destacar que o conceito de comunidade desempenha papel fundamental nas reflexões levadas a efeito por Tristan Engelhardt e por Jürgen Habermas, autores com os quais dialogaremos a seguir.

${ }^{6}$ Há entre os comentadores do autor consenso, explícito ou não, sobre o fato de que suas considerações sobre Bioética e saúde, campos que incessantemente o preocuparam, derivam de reflexões mais amplas sobre eticidade e moralidade, que envolvem política e religião. A título de exemplo, podemos citar Amado (2002). Nos concentraremos no livro "Fundamentos da Bioética", publicado em 1986, pois não temos razão suficiente para corroborar uma mudança de posição fundamental de Engelhardt em trabalhos posteriores.
} 
da estrutura da natureza ou dos meandros da história humana. Sem um substituto à altura para o que foi perdido, o bom senso poderia referendar um mundo desprovido de qualquer resposta inviolável sobre o que deve ser feito ou buscar em determinados valores - os seus -, a restauração da homogeneidade. A despeito de contraditar o ceticismo, esta orientação soaria como um lamento, como nostalgia de um passado em que o sentido da existência se sobrepunha ao poder de decisão do indivíduo.

Apesar de professar - de início, como católico e, posteriormente, como ortodoxo -, o cristianismo, crença que jamais fez questão de ocultar, inclusive em sua carreira acadêmica, Engelhardt não aventa a possibilidade de uma vida ética qualquer voltar a ocupar, em detrimento da multiplicidade das perspectivas morais, posição cêntrica ou até mesmo concêntrica. Esta conjectura admitiria que os indivíduos não são capazes de reconhecer que o seu patrimônio ético, herdado de um processo de socialização específico, deve ser reelaborado a partir de uma situação histórica que arrefece toda convicção de superioridade porventura transmitida. Interiorizado como totalidade categórica, sem lacunas a serem preenchidas por meio de aprendizagem, o mundo moral deve, por conseguinte, ser imutável. O contato com seus fundamentos sucede não entre os membros da comunidade, mas nas oportunidades em que se impõem a necessidade de generalizá-los. Tais fundamentos não se transmutam em objeto de reflexão para o exercício da crítica, mas, pelo contrário, para a ampliação do seu alcance objetivamente reiterado. Com efeito, o mundo social próprio, com o qual estes indivíduos se relacionam, sinceramente ou não, como dado, não se dilata, nem tampouco a autocompreensão se modifica.

Ora, em circunstâncias como esta, tão logo a plausibilidade do aprendizado é descartada, mecanismos coercivos ou dispositivos mais violentos de prescrição, que emergem dos que dominam, ocupam o palco. O problema fundamental consiste em que o tempo da aprendizagem - o tempo único da experiência, tanto para nós quanto para os outros, que não se mede cronologicamente -, não é ponderado. Engelhardt parece sugerir que, constatada a impraticabilidade da ascensão do ético para o moral, isto é, do particular para o universal, um universal que, para além da coincidência fortuita, materializa-se na síntese, devamos buscar refúgio, justamente para resguardar a concepção de autonomia, no princípio do consentimento, sugerido como mote facultativo para a efetivação da liberdade individual:

[...] Rebatizei o "princípio da autonomia" como o "princípio do consentimento" para indicar melhor que o que está em jogo não é algum valor possuído pela autonomia ou pela liberdade, mas o reconhecimento de que a autoridade moral secular deriva do consentimento dos envolvidos em um empreendimento comum. O princípio do consentimento coloca em destaque a circunstância de que, quando Deus não é ouvido por todos do mesmo modo (ou não é de maneira alguma ouvido por ninguém), e quando nem todos pertencem a uma comunidade perfeitamente integrada e definida, e desde que a razão não descubra uma moralidade canônica concreta, então a autorização ou autoridade moral secularmente justificável não vem de Deus, nem da visão moral de uma comunidade particular, nem da razão, mas do consentimento dos indivíduos (Engelhardt, 1998, p. 17)

Excluídos o divino, o comunitário e a razão, ou melhor, uma razão que não pode mais aspirar ao patamar outrora ocupado pela religião, a autoridade de uma moral plausível exige que a autonomia - conceito, pelo que se depreende, utilizado aqui para sacramentar, no tocante às suas repercussões práticas, a dualidade intocável entre noumênico e fenomênico -, remodele-se em torno de um potencial de consentimento cujos critérios não são patentes. O autor os conduz, sem maiores constrangimentos, ao próprio indivíduo, a um ator social que se define pela faculdade de autorreflexão, pela racionalidade e por ser portador de sentido moral. Tais qualidades, forjadas no campo de uma cultura peculiar, devem ser suficientes para traduzir convicções, cujo conteúdo é de imediato assentido por congêneres, em argumentos, em 
suposições que pleiteiam a sanção do outro. Para tanto, avança-se por um caminho discursivo em que o formalismo profere as regras. De todo modo, a "racionalidade" do resultado deste processo recíproco de persuasão não interrompe as suspeitas:

\begin{abstract}
A tentativa de sustentar um equivalente secular do monoteísmo cristão ocidental, por meio da revelação de uma única moral e narrativa metafísica da realidade, fragmentou-se em um politeísmo de perspectivas, com seu caos de diversidade moral e sua cacofonia de numerosas narrativas morais concorrentes. A racionalidade secular surge triunfante. Mas transformou-se em muitas racionalidades. Não está claro se ela pode proporcionar orientação moral ou metafísica (Engelhardt, 1998, p. 30).
\end{abstract}

Engelhardt sente-se completamente à vontade para jogar no mesmo tabuleiro movediço sobre o qual Maclntyre (2007, p. 53, tradução nossa) ${ }^{7}$ movimenta suas peças:

Conforme asseveram as novas teologias, a razão não pode reivindicar nenhuma compreensão genuína da verdadeira finalidade do homem. [...] Razão é cálculo; ela é capaz de proferir verdades factuais e de conceber relações matemáticas, nada além disso. Portanto, no domínio prático, ela somente pode falar sobre meios. Quanto a fins, tem que se calar.

Não obstante, Engelhardt atribui ao princípio do consentimento estímulo suficiente para delinear uma semântica comum que, ao romper as barreiras da linguagem privada, código que tipifica o multiculturalismo, viabiliza a aproximação comunicativa entre os assim denominados estranhos morais, caracterizados como indivíduos que se encontram impossibilitados de levar a efeito, em virtude de não compartilharem regras morais evidentes, deliberações racionais sobre controvérsias práticas, do mesmo modo que se recusam a assumir compromisso com pessoas ou instituições dotadas de capacidade e autoridade para tanto. Portanto, estes estranhos tomam parte em comunidades que se desconhecem e que, em sociedade, não puderam mais se ignorar. A eles se opõem os amigos morais, os que habitualmente se mantiveram próximos, devido a comungarem os mesmos valores substantivos atinentes ao certo, ao bem e ao virtuoso. Em tais circunstâncias, na existência inabalada de uma moral essencial, o entendimento sobre possíveis divergências quanto a procedimentos práticos não demandaria maior esforço comunicativo ${ }^{8}$. Alteradas as condições, a semântica comum - a gramática mínima que, à semelhança da linguagem natural, desenhada para ser prontamente aprendida, com vistas a atender ao telos do entendimento -, sucederia à moral essencial como medida para um ajustamento de ambições comprometido não com a reprodução de laços comunitários, mas com o despertar da tolerância, sem a qual inexistiria a oportunidade do acordo.

Diante da irreversível pluralidade de valores, a tolerância constituiria a salvaguarda contra o genuíno fermento para guerras: o fanatismo, tanto moral quanto religioso. Ambos procuram abrigo no poder estatal para fazer valer, desdenhando por completo do outro, uma visão de mundo (cosmovisão) particular. Assim como o intolerante religioso pretende transformar as instituições em meios destinados à conversão de infiéis, o moral as equipara a extensões do que compreende de modo absoluto por imparcialidade, justiça e igualdade. Por seu turno, ser tolerante não sugere negar convicções, mas acolher a escolha dos

\footnotetext{
${ }^{7}$ No original: Reason can supply, so these new theologies assert, no genuine comprehension of man's true end; that power of reason was destroyed by the fall of man. [...] Reason is calculative; it can assess truths of fact and mathematical relations but nothing more. In the realm of practice therefore it can speak only of means. About ends it must be silente (Maclntyre, 2007, p. 53).

${ }^{8}$ Engelhardt trabalha com a distinção entre comunidade e sociedade, termos que possuem relação intrínseca com as concepções de amigos e de estranhos morais, respectivamente. Segundo o filósofo americano, a comunidade consiste em "um corpo de homens e mulheres unidos por tradições e/ ou práticas morais comuns, ao redor de uma visão compartilhada da vida boa, que lhes permite colaborar como amigos morais" (Engelhardt, 1998, p. 26). Por sua vez, a sociedade corresponde a uma associação que envolve os indivíduos que se encontram em comunidades morais diversas.
} 
outros, ainda que, no âmbito de nossa perspectiva, espelhem preferências equivocadas. "Tolerância não significa que tenhamos de deixar de lado a condenação moral dos atos que achamos repreensíveis [...]. Não toleramos o bem; temos que tolerar aquilo que é mau" (Engelhardt, 1998, p. 47). Ou seja, continuaremos a censurar atos ou valores que julgamos imorais, porém eles contarão com nossa condescendência. Nestes termos, por intermédio do consentimento, o estranho não se torna meu amigo, mas se minimiza a possibilidade de ele vir a ser meu inimigo.

De um lado, a religião, acomodada nas narrativas primordiais dos textos sagrados, e a razão, alicerçada sobre preceitos de cunho metafísico; de outro, o acordo, um contrato que, sob nenhuma hipótese, pode pleitear universalidade, nem tampouco ser a expressão do racional. Em um contexto plural, no qual não há mais uma moralidade canônica à qual apelar, o que continuaria a conectar os seres humanas seria a preocupação com a efetivação de seus próprios interesses. Com efeito, cumpriria aos indivíduos, decididos a empregar esforço conjunto para lidar com desacordos, forjar uma nova autoridade moral que, abandonada por Deus e afastada em definitivo da razão, compense o desbaratamento da verdade com uma forma de intersubjetividade que, sem desestabilizar o que é específico a cada um, confira o contentamento dos anseios de todos. Em outros termos, ao renunciar ao universal, o consentimento se justifica por garantir a concretização possível de interesses particulares divergentes. Mais do que um acordo moral, Engelhardt propõe, para questões morais, o recurso a modelos de acordo que assegurem, sem modificações essenciais, a posição original dos contraentes. Este cânone do liberalismo asseguraria para a vida comunitária em sociedade a coesão e a confiança necessárias para a manutenção do contrato? Uma vez que o liberalismo, ao contrário do que propugnavam seus expoentes clássicos, consolidou-se como um sistema, tanto econômico quanto político, que se enraíza, conforme a terminologia weberiana, sob o terreno da racionalidade quanto a fins, não estaria o filósofo americano, além de descartar a razão substantiva, reconhecendo também que a moral deve ser avaliada, em seu formalismo, a partir de tal modelo de racionalidade? Por enquanto, é lícito sustentar que o autor, apesar de não apelar ao corte, considera o nó górdio da contemporaneidade impossível de ser desatado. De todo modo, antecipa um caminho tortuoso para afrouxá-lo.

A filosofia pós-metafísica, que designa o fracasso tanto da religião quanto do pensamento racional totalizante em disponibilizar, num cenário pautado pelo multiculturalismo, critérios morais indubitáveis, não poderia ser tomada, ao contrário do que muitos insistem em fazê-lo, como a confissão do fiasco do projeto iluminista. Antes disso, caberia remetê-la ao inacabamento e à persistência de uma concepção de racionalidade que permeou a modernidade, cujas características não se condensam em um núcleo substancial. Sem maiores pormenores, este é o trajeto que Habermas nos convida a percorrer quando, mormente em seus estudos de maturidade, se debruça sobre as relações cada vez mais intrincadas entre eticidade e moralidade.

O contínuo arrefecimento de imagens de mundo baseadas em doutrinas sentenciosas encontrar-se-ia condicionado por um processo de evolução social que estampa certas homologias com o desenvolvimento cognitivo e moral do indivíduo. É certo que a transição da explicação religiosa, passando pela ontológica, para procedimentos intersubjetivos voltados ao entendimento trouxe consigo senões sobre a viabilidade de identificação do universal. Se no campo da razão teórica - ou do Eu epistêmico -, as ciências naturais dirimiram a hesitação, no da razão prática - ou do Eu prático -, criou-se, pelo contrário, um vácuo, cujas iniciativas para o seu preenchimento resvalaram em generalizações, bem ou malsucedidas, de moralidades particulares, inaptas para transcender, na direção do que ainda poderia postular, sob a razoabilidade de alegações justificáveis, o encargo da universalidade. Assim, a moral permaneceria subsumida ao ético, até mesmo em sua diligência para sobrepujá-lo. 
Mais especificamente, no campo prático, as novas circunstâncias impuseram o surgimento de enfoques céticos - moderados ou intransigentes -, quanto à possibilidade de fundamentação de juízos morais. Na melhor das hipóteses, o que lhes dá respaldo deslizaria, concluída a revisão de uma autoconsciência que pretende julgar moralmente, para o terreno em que a racionalidade referente a fins, objetivamente mensurável, já se consolidou. Na pior, tais juízos, ainda que evidentes para os que os compartilham, apenas dissimulariam interesses e decisões de origem exclusivamente subjetiva, mais afeitos ao sentimento e à arbitrariedade das preferências. Ao fim e ao cabo, no que diz respeito às reivindicações morais, o assim denominado não-cognitivismo simplesmente suprimiria a razão ou redefiniria os critérios racionais que porventura podem fundamentá-las, demonstrando que se baseiam na utilidade instrumental.

De acordo com Habermas, para os próprios participantes de um jogo de linguagem moral travado em uma comunidade coesa, as normas que coordenam a ação tornam-se objeto de reflexão somente no caso de conflitos que não se dissolvem no nível em que se desenrola o cumprimento, de forma imediata, das expectativas habituais de comportamentos exigidas reciprocamente. Quando, por exemplo, um pedido de desculpas ou a admissão de uma falha não bastam, passa-se para um outro nível de interação, no qual a ação comunicativa prossegue sob a configuração de uma disputa discursiva sobre pretensões de retidão em torno do que efetivamente orientam as normas. Em outros palavras, posto que não são abandonadas, as regras reiteram, por intermédio de tais disputas, seu potencial imanente de convencimento:

Regras morais operam fazendo referência a si mesmas. Sua capacidade de coordenar as ações comprova-se em dois níveis de interação, acoplados de modo retroativo entre si. No primeiro nível, elas dirigem a ação social de forma imediata, na medida em que comprometem a vontade dos atores e orientam-na de modo determinado. No segundo nível, elas regulam os posicionamentos críticos em caso de conflito. Uma moral não diz apenas como os membros de uma comunidade devem se comportar; ela simultaneamente coloca motivos para dirimir consensualmente os respectivos conflitos de ação. Fazem parte do jogo da linguagem moral as discussões, as quais, do ponto de vista dos participantes, podem ser resolvidas convincentemente com a ajuda de um potencial de fundamentações igualmente acessível a todos (Habermas, 2002, p. 14).

Pelo que parece, a questão sobre a possibilidade de fundamentar regras morais não se coloca aos membros de uma comunidade. Seu teor cognitivo revela-se na força de convencimento que as acompanha tão logo são invocadas. Contudo, Habermas não sustenta que elas possam ser consideradas em si mesmas como racionais. Para entendê-las em sua autoridade, conviria então investigar minuciosamente o que ocorre em momentos nos quais os indivíduos julgam ter alcançado uma justificação moral convincente - isto é, devidamente fundamentada -, para as normas. O saber a elas imanente teria, portanto, natureza intersubjetiva. Com esta alegação, o filósofo alemão externo a intenção de desgarrá-las do alcance das objeções formuladas pelas correntes não-cognitivistas. O fato de rejeitarem outorgar à moral racionalidade seria o resultado necessário da insistência na preservação dos vínculos com o paradigma da consciência, mais precisamente com a ideia de que o sujeito se relaciona epistemicamente com o mundo mediante sua faculdade para constatar fatos e, por conseguinte, para enunciar proposições que possam corresponder a eles. Apenas assertivas - declarações cujo conteúdo, por consistir numa contingência logicamente autorizada, busca a rigor figurar a realidade -, possuiriam sentido. O uso semântico dos vocábulos verdadeiro ou falso estaria condicionado à viabilidade de tais figurações, cenário que denuncia a fundamentação inconsistente de mandamentos ou imperativos morais.

No entanto, a racionalidade para a qual se busca uma explicação seria de ordem distinta, já que ela desde sempre se acha inserida no mundo social, cujas exigências e expectativas são distintas daquelas que nos guiam quando nosso objeto de preocupação se refere ao mundo dos fatos: 
O fenômeno fundamental que a teoria moral necessita esclarecer consiste no caráter obrigatório de mandamentos e normas de ação. Neste aspecto, nós falamos de uma ética deontológica. Esta entende a correção das normas ou mandamentos por analogia com a verdade de uma sentença assertiva. Contudo, a "verdade" moral de expressões de dever não devem ser assimiladas [...] à validade assertiva de enunciados. [...] Conceituo a correção normativa como uma pretensão de validade análoga à de verdade. Neste sentido, falamos também de uma ética cognitivista, que poderia responder à questão de como fundamentar enunciados normativos (Habermas, 1988, p. 322, tradução nossa) $)^{9}$.

Se a teoria moral deixou de dispor do privilégio de se entrincheirar em refúgios metafísicos ou religiosos plenos de conteúdos exemplares, restaria a ela a opção de assumir um procedimento reconstrutivo, destinado a identificar - igualmente na esfera em que construções linguísticas que reivindicam o cumprimento de mandados dão o tom -, condições universais que possibilitam a compreensão mútua. A racionalidade não vem de fora. Ela se manifesta como pressuposto para atos de fala. Enquanto partícipes de um jogo de linguagem, todos nós nos submetemos às estruturas formais da comunicação, seja quando visamos ao entendimento ou ao consenso. À luz da pragmática proposta por Habermas, ações consensuais, antecipadamente autorizadas por processos orientados para o entendimento, são as responsáveis por instalar um acordo de base do qual emanam em situações cotidianas pretensões de validade previamente assentidas:

Com isso, as atuais teorias da justiça e da moral seguem caminhos próprios, em todo caso distintos dos da "ética", se a entendermos no sentido clássico de uma teoria da vida correta. [...] Exatamente nas questões que para nós têm maior relevância, a filosofia dirige-se a um meta-nível e investiga as características formais de processos de autocompreensão, sem tomar ela mesma posição quanto aos conteúdos. Isto pode ser insatisfatório, mas o que pode ser dito contra uma moderação bem justificada? (Habermas, 2005, p. 14, tradução nossa) ${ }^{10}$.

Este comedimento é parte integrante da estratégia reconstrutiva da filosofia habermasiana. Ao renunciar a conteúdos, ela equipara os jogos de linguagem moral e o faz, nunca é demais insistir, respaldado pelas propriedades formais da linguagem que viabilizam manifestações simbólicas interessadas em promover o entendimento. A fala, independentemente do que é tratado, está assentada sobre pretensões de validade que podem ou não chegar a bom termo. Com efeito, todos os proferimentos linguísticos orientam-se pelas intenções de clareza, de verdade, de correção e de veracidade. As pretensões de verdade, contidas em proposições que buscam representar fatos, e de correção, incluídas em imperativos ou mandamentos morais que se colocam em uma relação de justeza com as normas, são suscetíveis ao exercício da crítica. Em ambos os casos, os interlocutores podem demonstrar sua discordância: no primeiro, com a verdade pleiteada; no segundo, com a justeza postulada. Estas posições reivindicam que o emissor seja capaz de justificar, no plano discursivo, as respectivas pretensões manifestadas.

No que concerne à estratégia teórica ora em discussão, não obstante necessário, o formalismo universal que estrutura a comunicação possível não é suficiente para responder à pergunta sobre como

\footnotetext{
9 No original: Das moraltheoretisch erklärungsbe dürftige Grundphänomen ist nämlich die Sollgeltung von Geboten oder Handlungsnormen. In dieser Hinsicht sprechen wir von einer deontologischen Ethik. Diese versteht die Richtigkeit von Normen oder Geboten in Analogie zur Wahrheit eines assertorischen Satzes. Allerdings darf die moralische "Wahrheit" von Sollsätzen nicht [....] an die assertorische Geltung von Aussagesätzen assimiliert werden. [...] Normative Richtigkeit begreife ich als wahrheitsanalogen Geltungsanspruch. In diesem Sinne sprechen wir auch von einer kognitivitischen Ethik (Habermas, 1988, p. 322).

${ }^{10}$ No original: Deshalb gehen heute Theorien der Gerechtigkeit und der Moral eigene Wege, anderen jedenfalls als die"Ethik", wenn wir diese im klassischen Sinne als eine Lehre vom richtigen Leben verstehen. [...] Gerade in den Fragen, die für uns die grö te Relevanz haben, begibt sie sich auf eine Metaebene und untersucht nur mehr die Formeigenschaften von Selbstverständigungsprozessen, ohne zu den Inhalten selbst Stellung zu nehmen. Das mag unbefriedigend sein, aber was lässt sich gegen eine gut begründete Enthaltsamkeit ins Feld führen? (Habermas, 2005, p. 14).
} 
enunciados normativos podem ser fundamentados, principalmente em um contexto plural em que o contato, muitas vezes indesejado, entre diferentes formas históricas de vida cultural torna-se inevitável.

Isto posto, o passo seguinte é dado na direção de assinalar um princípio que, no campo das discussões sobre questões prático-morais, possibilite a construção de um consenso motivado por razões aceitas pelos participantes. Este princípio, entendido por Habermas como critério de universalização (U), sustenta que os efeitos colaterais surgidos do cumprimento geral das normas para o atendimento dos interesses de cada indivíduo possam ser anuídos, na ausência de qualquer mecanismo coercitivo, por todos os afetados. Nestes termos, $(U)$ remete a uma regra de argumentação deduzida a partir dos próprios pressupostos pragmáticos nela presentes. Com efeito, a ética do discurso teria, em última instância, como fundamento o princípio (D), que reza que toda norma válida teria que alcançar o consentimento de todos os impactados, desde que estes se envolvessem efetivamente em um discurso prático. Desnecessário dizer que os princípios elencados são contrafactuais. No entanto, ainda que apresentem caráter regulador, são simultaneamente constitutivos. Isto significa que seguem dos potenciais de racionalidade - ativos, porém ainda obstruídos em sua plena realização devido a interferências de fatores sistêmicos que lhe são exteriores -, imanentes à comunicação. Eis como em Habermas a ética firma um compromisso indissolúvel com uma teoria crítica da sociedade.

Nas éticas formais que abraçam a ideia de universalização $(U)$ sem atrelá-la, direta ou indiretamente, ao noumênico, a consumação do princípio discursivo (D) envolve a adoção de uma perspectiva sob a qual o que se ajusta ao interesse geral poderia ser apreciado de modo equânime. De acordo com Habermas (1999, p. 41, tradução nossa), não há prática argumentativa que não esteja integrada "à exigência de imparcialidade e à expectativa dos participantes questionarem e transcenderem as preferências que trazem consigo". À semelhança das regras de um jogo, que ditam de antemão os movimentos autorizados, o ponto de vista imparcial - ou ponto de vista moral -, constitui a conditio sine qua non para a participação em discursos prático-morais. Mediante ele, estariam endossadas a igualdade e a liberdade demandadas em uma busca cooperativa pelo correto, que somente pode consistir no resultado da força de convencimento dos melhores argumentos.

Para além disso, a imparcialidade que define o ponto de vista moral proporcionaria aos atores entretidos neste gênero de práxis comunicativa levar a efeito o que Habermas denomina transcendência a partir de dentro, o ir além dos limites da comunidade, visando, no próprio plano intramundano, compartilhado intersubjetivamente, discernir um olhar distanciado que abarque o mundo todo. Esta espécie de ascese profana revelaria, sob circunstâncias pós-metafísicas, a essência de questões genuinamente morais, responsáveis por nos conduzir ao campo da justiça, o que impõe o abandono, mesmo que efêmero, do interesse pelo tema referente ao conteúdo do que seria uma vida boa:

Assim, a formação do ponto de vista moral caminha de mãos dadas com uma diferenciação dentro do que é prático: as questões morais, que, sob o aspecto da capacidade de universalização de interesses, isto é, da justiça, podem ser decididas racionalmente, são agora diferenciadas das questões avaliativas, que se apresentam sob o aspecto geral de questões atinentes à vida boa (ou à autorrealização) e que são acessíveis à discussão racional somente dentro do horizonte não problemático de uma forma de vida historicamente concreta ou de um comportamento vital individual (Habermas, 1984, p. 225, tradução nossa) ${ }^{11}$.

\footnotetext{
11 No original: So geht die Herausbildung des moralischen Gesichtspunktes mit einer Differenzierung innerhalb des Praktischen Hand in Hand: die moralischen Fragen, die unter dem Aspekt der Verallgemeinerungsfähigkeit von Interessen oder der Gerechtigkeit grundsätzlich rational entschieden warden können, werden nun von den evaluativen Fragen unterschieden, die sic hunter dem allgemeinsten Aspekt als Fragen des guten Lebens (oder Selbstverwirklichung) darstellen und die einer rationalen Erörterung nur innerhalb des unproblematischen Horizonts geschichlich konkreten Lebensform oder einer individuellen Lebensführung zugänglich sind (Habermas, 1984, p. 225).
} 
O novo patamar de racionalidade ao qual este procedimento abstrativo alça o juízo prático compele à problematização do horizonte ético sob cujos contornos o indivíduo socializou-se e forjou uma ideia de moralidade que jamais submeteu à dúvida a vida desejada por ele e por sua comunidade, da qual sempre extraiu motivação para ações concretas. Este papel crítico a ser doravante desempenhado fincaria suas raízes mais profundas no desenvolvimento do eu prático, no estágio universalista em que prevalece uma forma de consciência moral pós-convencional, conforme a terminologia de Kohlberg. Neste estágio, que, de um ponto de vista epistêmico, coincidiria com a aquisição da capacidade de julgar reflexivamente, as pretensões de validade presentes em normas e mandamentos, responsáveis por ações coordenadas que estabilizam as relações entre integrantes de grupos comunitários, passariam a ser apreciadas como convenções, como construções voltadas à legitimação do existente. Para compensar a suspensão de evidências até então tidas como absolutas, ou melhor, a substituição de motivos empíricos objetivos por procedimentos formais, Habermas lança mão de uma concepção de moralidade cuja fundamentação - capaz não apenas de possibilitar juízos morais baseados em princípios universais, mas também de motivar ações em conformidade com eles -, consiste na hipótese de que ela constituiria o cerne das manifestações do ético:

[...] Sustento o conceito de moral universal como um núcleo que, sob o invólucro das formas de vida ética, pode assumir aspectos historicamente diferentes. Quem deixa este ponto de referência, quem mantém as morais locais circunscritas ao círculo de encantamento da eticidade concreta, perde a medida racional para apreciar formas de vida ética (Habermas, 1984, p. 226, tradução nossa) ${ }^{12}$.

Eis o retorno da moral ao concreto. Mas não seria uma volta qualquer, um retroceder ao ponto de partida preservado intacto. A aprendizagem ocasionada pelo recurso a procedimentos formais modificaria o modo de lidar racionalmente com conteúdos experienciáveis no mundo vivido (Lebenswelt). As intuições morais, a consideração e o respeito pela pessoa, não mais se centrariam exclusivamente na proteção dos congêneres. Antes disso, é com a figura do outro, daquele que persevera em resguardar sua alteridade, que a comunidade, já de posse de uma perspectiva inclusiva dos que são dignos de solidariedade, teria que se responsabilizar. Como Habermas a concebe, a justiça firma, por meio de processos discursivos voltados ao consenso, o reconhecimento simétrico de cada um e de todos. Por conseguinte, a comunidade poderia remarcar, sob novas divisas, o espaço que lhe cabe diante da sociedade; na verdade, essa constelação sugeriria a possibilidade de ruptura da falsa dualidade entre elas. Para tanto, todavia, haveria a necessidade de convergência histórica entre o potencial de racionalidade imanente às pretensões de validade que estruturam a linguagem como tal e as características acidentais contraídas pelas instituições políticas. Estas, juntamente com a comunicação, comporiam os polos indissociáveis para a inteligibilidade do que se propugna como forma de vida racional.

A prerrogativa inalienável do uso autônomo da razão, o que torna suscetível ao escrutínio do convencimento discursivo toda e qualquer convicção prévia, o direito ao exercício, no ambiente da esfera pública, do papel de cidadão, que em regra, quando esclarecido, se sobrepõe àquele que se confunde com a defesa dos interesses do indivíduo privado ou do membro de uma comunidade específica, a garantia de que uma subjetividade descentrada, capacitada a se entregar ao trabalho com hipóteses explicativas e com concertos ético-legais carentes de justificação, enfim, as propriedades que singularizariam o estágio em que a moral elevou-se ao nível pós-convencional, encontrariam o seu corresponde, não somente jurídico, mas também em termos de homologias com imagens de mundo, nos preceitos liberais, que

\footnotetext{
12 No original: [..] halte ich am Begriff der universalistischen Moral als dem Kern fest, der in der Schale sittlichen Lebensformen historisch Verschiedene Gestalten annehmen kann. Wer diesen Bezugspunkt preisgibt, wer lokale Moralen im Bannkreis Konkreter Sittlichkeit eingeschlossen hält, begibt sich des vernünftigen Ma stabes für die Beurteilung sittlicher Lebensformen (Habermas, 1984, p. 226).
} 
reivindicam uma construção ideologicamente neutra, na dimensão institucional do Estado democrático de Direito. Embora idealizada, esta concepção, sem nenhuma contradição aparente, uma vez que que estaria apenas antecipando uma situação cuja efetivação mostra-se compatível com a plena concretização dos fatores que definem o fenômeno, traria para o campo institucional o formalismo - e, com ele, o seu potencial -, exigido pelas regras racionais que autorizam o discurso prático:

Estas pressuposições idealizadas exigem a completa inclusão de todos os possivelmente atingidos, a igualdade de direitos dos participantes, o desembaraço para a interação, a franqueza dos temas e das contribuições, a possibilidade de revisão dos resultados etc. Com efeito, os processos legais servem para fazer valer as coerções de escolha espacial, temporal e substantiva na sociedade real como numa comunidade comunicativa idealmente suposta. Assim, por exemplo, as regras da maioria deixar-se-iam interpretar como um acordo que a construção da opinião dirigida à verdade, ao fim e ao cabo, segundo a possibilidade discursiva, compatibiliza com a coerção para a formação da vontade temporalmente determinada. De acordo com a abordagem teórico-discursiva, a decisão da maioria tem que manter uma relação interna com a práxis argumentativa, da qual resultam outras medidas institucionais [...] (Habermas, 1999, p. 41, tradução nossa) ${ }^{13}$

Inserida no processo de secularização, a neutralização ideológica do Estado não seria suficiente, nem tampouco poderia sê-lo, para a constituição de uma esfera pública em que, em última instância, conteúdos substanciais não mais determinassem a performance comunicativa de alguns dos participantes. A pluralidade instituída, manifestada nos direitos subjetivos dos indivíduos, também autorizaria os membros de comunidades, reconhecidos equitativamente como cidadãos, a submeter ao crivo da crítica, dirigida exclusivamente pela força impositiva do melhor argumento, suas respectivas cosmovisões. Contudo, exigir-se-ia para tanto um esforço de tradução. Neste contexto, a linguagem religiosa, para que aspire ao convencimento dos que não se posicionam como crentes e assim possa vislumbrar a conquista de maiorias, necessitaria ser vertida para um conjunto de pretensões de validade cuja aprovação somente seria passível de ocorrer em uma arena na qual as reivindicações discursivas encarregam-se da responsabilidade pela consolidação de formas democráticas de existência comum.

De acordo com Habermas, tais iniciativas de racionalização, tomadas com vistas à adequação aos novos critérios de universalidade, são em regra interpretadas pelos crentes como uma via de mão única. Para eles, a tradução de suas convicções careceria de uma contrapartida, já que as objeções que formulam em virtude de se sentirem lesados por orientações seculares que contraditam a essência da fé são antecipadamente recusadas, como se não houvesse nenhuma racionalidade nelas. Esta censura teria como consequência privar a sociedade secularizada do contato com uma imprescindível fonte de sentido, capaz de disponibilizar aos indivíduos concepções que não podem ser compensadas nem pelo conhecimento científico, muito menos por expectativas produzidas pelo mercado.

Sob condições democráticas, seria de se esperar inclusive que os cidadãos secularizados cooperassem para descobrir, na mentalidade e em declarações religiosas, intuições e conteúdos semânticos que, mediante tradução, poderiam ser tematizados em argumentações públicas. Ao pé da letra, a cidadania comum constrangeria ambos os lados a desenvolverem em conjunto, cada um a partir de seu ponto de vista, uma interpretação da relação entre fé e saber que propiciasse uma coexistência completamente aberta a formas de aprendizagem que envolvam procedimentos contínuos de autocompreensão:

\footnotetext{
${ }^{13}$ No original: Diese idealisierenden Voraussetzungen verlangen die vollstädige Inklusion aller möglicherweise Betroffen, die Gleichberechtigung der Parteien, Zwanglosigkeit der Interaktion, Offenheitfür Themen und Beiträge, Revidierbarkeit der Ergebnisse usw. In diesem Zusammenhang dienen die rechtlichenen Prozeduren dazu, die in der realen Gesellschaft auftretenden Selektionszwänge räumlicher, zeitlicher und sachlicher Art innerhalb einer als ideal unterstellten Kommunikationsgemeinschaft zur Geltung zu bringen. So lä tsich beispielsweise die Mehrheitsregel al sein Arrangement verstehen, das eine nach Möglichkeit discursive, letztlich wahrheitsorientierten Meinungsbildung mit dem Zwang zur zeitlich terminierten Willensbildung kompatibel macht. Nach der diskurstheoretischen Lesart mu die Mehrheitensentscheidung eine interne Beziehung zur Argumentationspraxis aufrechterhalten, woraus sich weitere Institutionelle Vorkehrungen [...] (Habermas, 1999, p. 41).
} 
A neutralidade ideológica do Estado, que assegura a todos liberdades éticas idênticas, é inconciliável com a universalização política de uma visão de mundo secularizada. Os cidadãos secularizados, ao desempenharem o papel de cidadãos do Estado, não podem nem contestar, sem a devida consideração, o potencial de verdade das cosmovisões religiosas, nem negar aos concidadãos religiosos o direito de contribuir, por meio de sua própria linguagem, para a discussão pública. Uma cultura política liberal pode até mesmo esperar dos cidadãos secularizados a participação nos esforços de tradução das contribuições relevantes da linguagem religiosa para uma linguagem publicamente acessível (Habermas, 2007, p. 57)

Caminhado contra a corrente, Habermas objetivamente dobra a aposta no projeto iluminista. Para além das realizações sacramentadas pelo uso teórico-instrumental da razão, o filósofo alemão insiste que, no que versa sobre seu uso prático, poderíamos chegar a um consenso similar. Ou seja, respostas às questões morais, desde que validadas intersubjetivamente, disporiam de uma segurança que as credenciariam a ocupar um status que, para os participantes deste jogo de linguagem, cujas possibilidades de ampliação, resultantes dos processos de aprendizagem que lhes são pertinentes, progressivamente se evidenciam, corresponderiam ao que, no domínio do conhecimento científico, recebe o nome de verdade.

Decerto, em virtude sua própria natureza, as pretensões de validade em torno das quais os juízos práticos buscam legitimação são mais suscetíveis a obstruções, a interferências de uma racionalidade que Ihe permanece estranha. Não por acaso, a feição mais evidente da crise que intimida a contemporaneidade revelaria traços pertencentes ao fenômeno da colonização do mundo da vida pelo mundo sistêmico, da submissão das forças produtivas da comunicação à lógica do mercado e do poder político.

Finalizado o enredo que dita a construção da estratégia teórica, Habermas parece encontrar em um único movimento as linhas desencadeadoras do nó górdio de nosso século e a passagem para deslindá-lo. Problemas morais reclamariam respostas de cunho moral. Estas teriam como medida exclusiva a possibilidade de serem assumidas como justas por todos os concernidos. A correção das normas seria aferida no plano discursivo. Quando os juízos prático-morais deixam-se determinar pela linguagem do cálculo, mensurada pelo êxito objetivo, o ponto nodal emerge. O nó se ata pela linguagem e é por meio desta que tem de ser desfeito. Enfim, o enigma do desafio é decifrado.

Não faltaram críticas ao modelo dual de racionalidade consignado pelo filósofo alemão. Quase todas elas denunciam o caráter excessivamente idealista atribuído ao potencial comunicativo, que, em termos sociológicos, beiraria a ingenuidade. Engelhardt (1998, p. 81), por exemplo, o considera impossível de ser sondado, uma vez que as normas imparciais das quais depende seu alcance universal já pressupõem, caso venham a ser adotadas, um padrão específico de moralidade:

Mas é a especificação geral e a possibilidade de testar as normas morais que é impossível. Ou essas normas seculares não existem, ou não podem ser testadas sem pressupor o que está em jogo: um sentido moral particular ou uma noção de racionalidade moral. Por isso é intangível a esperança do iluminismo em uma narrativa moral universal, uma explicação da vida moral ou comunidade moral essencial.

Para contrapô-las, Habermas, desde os anos 1970, sem maiores senões, apela à história da espécie humana, portadora de um desenvolvimento que reservaria lugar específico à linguagem, cuja racionalidade apresentaria indícios próprios, constatáveis por meio de processos reconstrutivos:

Nessas pretensões de validade, a teoria da comunicação pode procurar uma pretensão de razão branda, porém obstinada, nunca silenciada, embora raramente cumprida, que, no entanto, precisa de facto ser reconhecida, em todos os lugares e todas as vezes que uma ação for efetivada. Se 
isso for idealismo, então esse idealismo pertence, de modo altamente naturalista, exatamente às condições de reprodução de uma espécie que deve conservar sua vida mediante trabalho e interação, ou seja, também em virtude de proposições passíveis de serem verdadeiras e de normas carentes de justificação (Habermas, 2015, p. 28, grifo do autor).

\section{Conclusão}

O decurso da aprendizagem desenrola-se quando nos defrontamos com problemas epistêmicos ou prático-morais cuja resolução não pode mais ser localizada nos saberes que se encontram à disposição. Em tais momentos, cada vez mais recorrentes, nossas faculdades devem ser postas em ação, buscando alternativas. Na dimensão tecnocientífica, as respostas às demandas, por mais complexas que sejam, não tardam a aparecer. O conhecimento instrumental e o aparato tecnológico acessíveis no 11 de setembro há muito se tornaram obsoletos, fato que reitera a extraordinária capacidade de inovação de um gênero que evolui linearmente pelo trabalho social. Por seu turno, na da comunicação, o único meio em que, sob a secularização e o consequente pluralismo, a moralidade ainda pode se atrever a cobiçar universalidade, houve uma inflexão, acarretada por fatores político-econômicos. Tal desvio não nos legou nada de diferente. Muito pelo contrário, aparenta ter nos conduzido a um patamar, com as distinções de praxe, semelhante ao da primeira metade do século passado.

Assim como antes, a Realpolitik, a eficiência imediata que se revela no corte abrupto do nó, continua a produzir, a médio e longo prazos, efeitos piores do que aqueles que de início pretendia sanar. Problemas até então restritos à política internacional de súbito adquiriram expressão nacional. Os outros, aqueles que mantínhamos na penumbra de um desconhecimento deliberado, tornaram-se não estranhos, mas inimigos morais, inacessíveis ao diálogo. Os que me eram próximos, não como membros da comunidade na qual me reconheço entre iguais, mas como indivíduos portadores de direitos subjetivos idênticos aos meus, distanciaram-se à maneira daqueles que, em defesa de valores que violam a mim e àquilo que me cumpre estender, constituem um empecilho à imagem exemplar da boa vida.

Ao se pronunciar sobre o ataque ao World Trade Center e ao Pentágono, em um período em que a pesquisa genética tematizava o conflito entre o secular e o religioso, Habermas o insere na problemática mais ampla de um déficit comunicativo. O terrorismo, para além de sua inaceitável violência muda, indicaria um choque entre culturas contra o qual mísseis e invasões pouco ou quase nada podem fazer. O seu equacionamento exigiria a insistência no trabalho - extremamente moroso, mas muito menos dispendioso em termos de vidas humanas - de estabelecimento de uma linguagem comum comprometida com o justo, o que obrigaria ambos os lados a suspender aquilo que julgam ser um modelo acabado de sociedade correta.

Nesta mesma oportunidade, o autor chamava a atenção para o fato de o fundamentalismo não ser exclusividade dos mulçumanos. Também entre cristãos e judeus haveria o recrudescimento de posições ortodoxas radicais, fenômeno que demonstraria o quão dialético é o processo de secularização no mundo ocidental. Em tal cenário, cumpriria ao Estado liberal atuar no sentido de evitar que as comunidades religiosas voltassem a se valer de mecanismos de imposição de suas verdades de fé já tidas como proscritos.

Os últimos vinte anos acentuaram os obstáculos a uma convivência pacífica entre grupos plurais. Mesmo em democracias consolidadas, as regras da maioria, que poderiam ser tomadas como expressão temporal e substantiva de uma concepção de racionalidade comunicativa idealizada, distanciaram-se do propósito regulador que as toma como opinião - discursivamente construída - dirigida à verdade. 
O necessário esforço de tradução da linguagem religiosa para uma linguagem pública interrompeu-se. Na realidade, impera atualmente um fenômeno oposto: a tradução da linguagem pública para uma linguagem religiosa excludente. À luz das perspectivas teóricas aqui abordadas, esta inversão inviabiliza por completo os processos de aprendizagem imprescindíveis ao equilíbrio da sociedade secular. Tanto o formalismo moral de Habermas, com o qual o filósofo alemão pretende justificar a possibilidade de normas universalmente válidas, quanto o princípio do consentimento de Engelhardt, a opção apresentada pelo autor para o que ele entende ser o entrave insuperável para fazer da razão o substituto de Deus, dependem, apesar de suas evidentes distinções, do desenvolvimento de uma linguagem comum. Isto posto, não teria chegado a hora de admitirmos o malogro da comunicação em cumprir o papel de saída para o problema da intolerância e, com efeito, em assegurar a racionalidade das instituições políticas, aproximando-as de uma moralidade que visa à inclusão de todos? Se sim, o que deveria ocupar este espaço vazio?

\section{Referências}

Amado, E. D. De moralidad y eticidad: dos dimensiones para la Bioética. Acta Bioética, v. 8, n.1, p. 9-19, 2002. Engelhardt, H.T. Fundamentos da bioética. São Paulo: Loyola, 1998.

Habermas, J. A inclusão do outro: estudos de teoria política. São Paulo: Loyola, 2002.

Habermas, J. Begründete Enthalsamkeit: gibt es postmetaphysische Antworten auf die Frage nach dem "richtigen Leben"? In: Habermas, J. Die Zukunft der menschlichen Natur: auf dem Weg zu einer liberalen Eugenik? Frankfurt am Main: Suhrkamp, 2005.

Habermas, J. Glauben und Wissen. Frankfurt am Main: Suhrkamp, 2001.

Habermas, J. Moralität und Sittlichkeit: treffen Hegels Einwände gegen Kant auch auf die Diskursethik zu? Revue Internationale de Philosophie, v. 42, n. 166, p. 320-340, 1988.

Habermas, J. Para a reconstrução do materialismo histórico. São Paulo: Unesp, 2015.

Habermas, J. Über Moralität und Sittlichkeit - was macht eine Lebensfom "rational". In: Schnädelbach, H. (org.). Moralität: philosophische Beiträge. Frankfurt am Main: Suhrkamp, 1984.

Habermas, J. Fundamentos pré-políticos do estado democrático de direito? In: Habermas, J.; Ratzinger, J. Diáletica da secularização: sobre razão e religião. Aparecida: Ideais \& Letras, 2007.

Habermas, J. Vorwort zur Neuauflage 1990. In: Habermas, J. (org.). Strukturwandel der Offentlichkeit: untersuchungen zu einer Kategorie der bürgerlichen Gesellschaft. Frankfurt am Main: Suhrkamp, 1999.

MacIntyre, A. After virtue: a study in moral theory. Notre Dame: University of Notre Dame Press, 2007.

Negt, O.; Kluge, A. Maßverhältnisse des Politischen. In: Negt, O.; Kluge, A. Maßverhältnisse des Politischen: 15 Vorschläge zum Unterscheidungsvermögen. Frankfurt am Main: Fischer, 1992. p. 13-53.

Como citar este artigo/How to cite this article

Campato, R. F.; Silva, P. F.; Campato Junior, J. A. Eticidade e moralidade em sociedades seculares: o que pudemos e ainda podemos aprender com o 11 de setembro?. Reflexão, v. 46, e215504, 2021. https://doi.org/10.24220/2447$6803 v 46 e 2021 a 5504$ 